\title{
Acidogenic Potential of "Sugar-Free” Cough Drops
}

\author{
John A. Mayo ${ }^{1,2, \#, *}$ and John R. Ritchie ${ }^{3}$
}

Departments of ${ }^{1}$ Microbiology, Immunology, and Parasitology, ${ }^{2}$ Periodontics, and ${ }^{3}$ Comprehensive Dentistry, School of Dentistry, Louisiana State University Health Sciences Center, New Orleans, LA 70119 and ${ }^{\#}$ Present address: Department of Biochemistry and Molecular Biology, University of Georgia, Athens, GA 30602-7229 USA

\begin{abstract}
A patient presented with extensive marginal ditching around restorations recently placed during whole-mouth rehabilitation. The patient was not xerostomic and was otherwise normal except for the self-reported excessive use of "sugar-free" cough drops sweetened with sorbitol and Isomalt ${ }^{\circledR}$ (an equimolar mix of glucosyl-mannitol and glucosylsorbitol). This prompted an in vitro investigation to determine whether Streptococcus sobrinus 6715, a cariogenic streptococcus, could grow and produce acid in growth medium containing an aqueous extract of such "sugar-free" cough drops. The results indicate that $S$. sobrinus 6715 uses Isomalt ${ }^{\circledR}$ and sorbitol extensively, producing terminal culture $\mathrm{pH}$ as low as 4.2 when grown on medium with cough drop extract containing these sugars. This $\mathrm{pH}$ is sufficient to demineralize dental enamel. Patients should be cautioned against the chronic overuse of "sugar-free" cough drops and other "sugar-free" confections sweetened with a mixture of Isomalt ${ }^{\circledR}$ and sorbitol.
\end{abstract}

\section{INTRODUCTION}

Dental caries remains one of the three most common infectious diseases in the world [1]. A major risk factor for this disease is the frequent ingestion of sugars (especially sucrose) that can be rapidly fermented by oral bacteria, producing sufficient acid to dissolve dental enamel $[2,3]$. While highly acidogenic and adherent organisms such as Streptoccoccus mutans and $S$. sobrinus have been implicated as primary pathogens, it has become evident that other acidogenic bacteria are present in significant numbers in carious lesions and may be important in lesion progression. These include so-called low-pH non-mutans streptococci as well as members of the genera Lactobacillus, Actinomyces, Atopobium, Bifidobacterium, Propionibacterium, and Veillonella [4].

According to the Ecological Plaque Hypothesis, frequent ingestion of sucrose and other fermentable sugars can produce regular and prolonged low $\mathrm{pH}$ in dental plaque. These acidic conditions provide a selective pressure that allows acidogenic and acid-tolerant bacteria such as the mutans streptococci and lactobacilli to become dominant in the dental plaque microbial community, while at the same time suppressing non-cariogenic components of the oral microbiota $[5,6]$. Thus, the suppression of acid-producing bacterial metabolism by metabolic inhibitors and the replacement of sucrose with non-fermentable sweeteners in foodstuffs have been among the goals of caries control [2, 5-7].

Non-fermentable sweeteners can be high-intensity (saccharin, aspartame, sucralose) or carbohydrate [2]. Nonfermentable carbohydrate sweeteners are polyols (sugar alcohols) and include sorbitol, hydrogenated glucose syrups, Isomalt $^{\circledR}$ (an equimolar mixture of $\alpha$-D-glucopyranosyl -1,6-

*Address correspondence to this author at the Department of Biochemistry and Molecular Biology, A322 Davison Life Sciences Complex, University of Georgia, Athens, GA 30602-7229 USA; Tel: +1-706-542-1713; Fax: +1706-542-3719; E-mail: jmayo@uga.edu sorbitol and $\alpha$-D-glucopyranosyl -1,6-mannitol) and others. These polyols are regarded as "tooth-friendly"; i.e., they do not promote dental caries $[2,8]$, and studies have demonstrated minimal, short-duration $\mathrm{pH}$ falls after brief exposure of dental plaque to polyols in plaque telemetry experiments [9] and very low cariogenicity compared to sucrose in animal experiments [10].

An adult patient at the Louisiana State University School of Dentistry in New Orleans was treated for rampant caries with a complete full-mouth restoration. Approximately one year later the patient returned to the clinic with extensive ditching around the margins of the new restorations. Staining and ditching at margins of restorations have been suspected as indicators of marginal or secondary caries [11]. Margins with ditches of $0.4 \mathrm{~mm}$ or greater contain high numbers of bacteria, mutans streptococci, and lactobacilli compared to clinically intact margins or margins with narrow ditches [12], suggesting a possible microbial etiology for at least some marginal ditching. The patient in question had normal salivary flow and normal dental and medical histories, except for the use of 8-12 so-called "sugarless" or "sugar-free" cough drops per day during the preceding year. The brand used by the patient was sweetened with aspartame, hydrogenated glucose syrup, and Isomalt ${ }^{\circledR}$, and was marketed as "sugar-free".

The purpose of the present study was to examine in vitro whether a known cariogenic streptococcus could metabolize sweeteners from "sugar-free" cough drops to produce acid sufficient to demineralize dental enamel.

\section{MATERIALS AND METHODS}

\section{Cough Drop Extract}

"Sugar-free" cough drops of the same brand and flavor used by the patient in question were purchased at a local 
pharmacy. The listed sweetening agents included aspartame, hydrogenated glucose syrup, and Isomalt ${ }^{\circledR}$; amounts or concentrations were not given. Other ingredients were menthol, canola oil, FD\&C Blue \#1 Aluminum Lake, and flavors.

Cough drops from several packages were unwrapped, pooled, weighed, and dissolved in deionized water. After filtration (Whatman \#1) to remove oil, extracts were slightly turbid with a faint blue to blue-green color. In separate preparations, extracts were diluted with deionized water to give concentrations of 280 and $500 \mathrm{mg} / \mathrm{ml}$, based on weight of the unwrapped cough drops. Extracts were stored at $20^{\circ} \mathrm{C}$. Aliquots were thawed and sterilized by membrane filtration immediately before use.

\section{Bacteria and Bacterial Growth}

Streptococcus sobrinus 6715 , a highly cariogenic strain [13], was obtained from the culture collection of the Department of Microbiology, Immunology, and Parasitology, Louisiana State University Health Sciences Center, New Orleans. Cultures were grown essentially as previously described [14] using a Trypticase peptone medium [15]. Briefly, basal medium was sterilized (autoclave), after which separately sterilized (membrane filtration) growth sugars were added aseptically. Growth sugars included glucose, mannitol, sorbitol, and cough drop extract, with sugar concentrations as indicated in Fig. (1) and Tables $\mathbf{1}$ and 2. Growth was determined by measuring culture absorbance at $660 \mathrm{~nm}\left(\mathrm{~A}_{660}\right)$ and culture terminal $\mathrm{pH}$ was determined with a $\mathrm{pH}$ meter.

For growth-terminal $\mathrm{pH}$ experiments, cultures $(10 \mathrm{ml}$, $18 \times 150 \mathrm{~mm}$ culture tubes) were incubated at $37^{\circ} \mathrm{C}$ without mixing for 48-72 hours. For pH-controlled growth, a $500 \mathrm{ml}$ culture containing cough drop extract $(50 \mathrm{mg} / \mathrm{ml})$ was grown as described [14] for 62 hours at $37^{\circ} \mathrm{C}$ with gentle stirring. The $\mathrm{pH}$ was maintained at 6.5 by periodic addition of $0.2 \mathrm{M}$ $\mathrm{KOH}$ using a $\mathrm{pH}$ controller (Cole-Parmer). After removal of

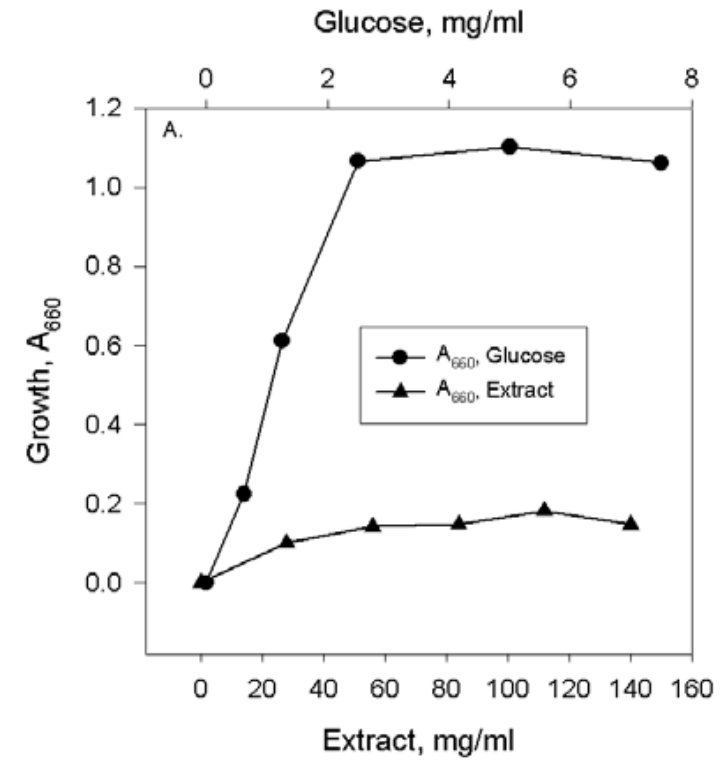

bacterial cells by centrifugation, the supernatant fluid was sterilized (membrane filtration) and submitted for analysis of residual sugars. A sample of sterile uninoculated growth medium was retained as a control for sugar analysis.

\section{Sugar Analysis}

Sugar analysis was done by high-pressure liquid chromatography (HPLC) essentially as described [16], using a Dionex HPLC with CarboPac PA10 column (4x250 mm), Dionex ED40-1 pulsed amperometric detector, and $100 \mathrm{mM}$ $\mathrm{NaOH}$ as the eluent. Chromatographic standards (glucose, mannitol, sorbitol, and Isomalt ${ }^{\circledR}$ ) were obtained from Sigma.

\section{RESULTS}

\section{Growth and Acid Production in Medium Containing Cough Drop Extract (CDE)}

Growth and terminal pH of Streptococcus sobrinus 6715 in medium containing either CDE or other sugars are shown in Fig. (1) and Table 1. Growth and terminal $\mathrm{pH}$ as functions of sugar concentration are shown in Fig. (1). Growth, measured as final culture turbidity $\left(\mathrm{A}_{660}\right)$ is shown in Fig. (1A); values are corrected for the scant growth that occurred in medium with no added sugar. The results indicated that $S$. sobrinus 6715 could grow in medium containing $\mathrm{CDE}$ as the sugar source, although the biomass yield was less than $20 \%$ of that obtained with the preferred substrate glucose.

Acid production, measured as terminal culture $\mathrm{pH}$, is shown in Fig. (1B). Measurements of $\mathrm{pH}$ were done on the same cultures for which $\mathrm{A}_{660}$ had been measured in Fig. (1A). CDE was shown to be an acidogenic substrate for $S$. sobrinus 6715. Terminal $\mathrm{pH}$ decreased as CDE concentration increased, reaching a terminal $\mathrm{pH}$ as low as 4.2. Glucose was even more acidogenic, with a low terminal $\mathrm{pH}$ of 3.7. Also shown in Fig. (1B) are reference lines representing the possible range of the so-called critical $\mathrm{pH}$ at which dental

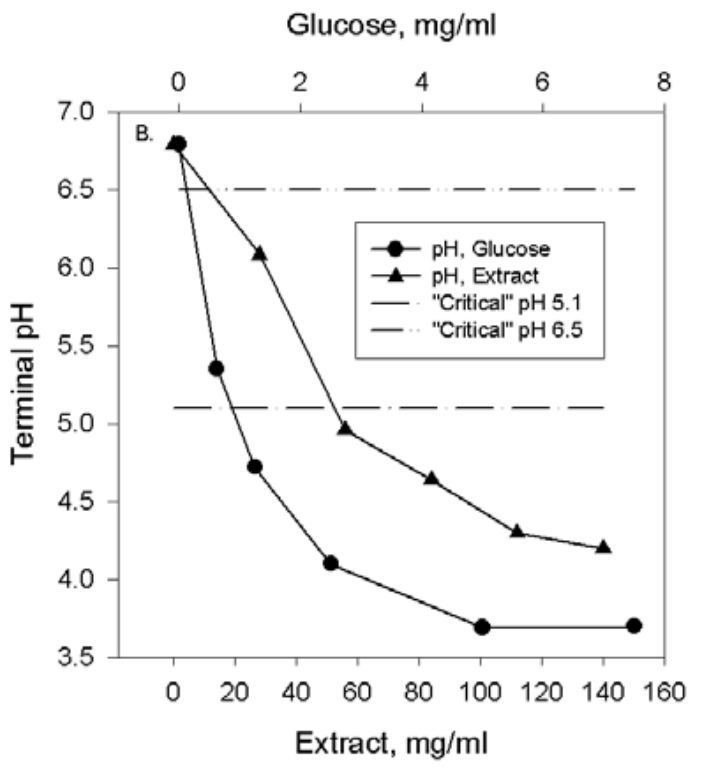

Fig. (1). Growth and terminal pH of cultures of Streptococcus sobrinus 6715 grown in liquid medium containing varying concentrations of glucose or Cough Drop Extract (CDE). Note dual X-axes above (glucose) and below (CDE) each graph. Fig. (1A): Growth measured as $\mathrm{A}_{660}$. Fig. (1B): Terminal pH. Also shown in Fig. 1B are the extreme values for the so-called "critical pH" for the dissolution of dental enamel in oral fluids [17]. 
enamel could dissolve in dental plaque fluid ( $\mathrm{pH} 5.1$ ) or in saliva with low concentrations of calcium and phosphate ions ( $\mathrm{pH}$ 6.5) [17].

Growth and terminal $\mathrm{pH}$ of $S$. sobrinus 6715 cultures grown in medium supplemented with $\mathrm{CDE}$ or its constituent sugars is shown in Table 1. Glucose, mannitol, and sorbitol are components of Isomalt ${ }^{\circledR}$, and sorbitol is the major free constituent of hydrogenated glucose syrup [18]. Aspartame, the remaining sweetener, is not metabolized by bacteria to produce acid [9]. Scant growth and approximately neutral $\mathrm{pH}$ were observed in medium with no added sugar, while all other sugars produced both growth and terminal $\mathrm{pH}$ at or below that which would dissolve enamel under plaque at a tooth surface. An average cough drop weighed 3.65 grams (data not shown). Thus, $50 \mathrm{mg}$ of CDE per $\mathrm{ml}$ of culture corresponded to approximately $1.4 \%$ of a single cough drop.

Table 1. Growth and Terminal pH in Cultures of Streptococcus sobrinus 6715 Grown in Trypticase Broth Supplemented with Sugars or Cough Drop Extract (CDE)

\begin{tabular}{|c|c|c|}
\hline Sugar & $\mathbf{A}_{660}$ & $\mathbf{p H}$ \\
\hline \hline None & 0.27 & 6.79 \\
\hline CDE, $50 \mathrm{mg} / \mathrm{ml}$ & 0.40 & 5.12 \\
\hline Glucose, $4 \mathrm{mg} / \mathrm{ml}$ & 1.31 & 3.90 \\
\hline Mannitol, $4 \mathrm{mg} / \mathrm{ml}$ & 0.90 & 4.42 \\
\hline Sorbitol, $4 \mathrm{mg} / \mathrm{ml}$ & 0.57 & 4.86 \\
\hline
\end{tabular}

\section{Analysis of Residual Sugars After Growth of $S$. sobrinus 6715 in Medium Supplemented with CDE}

HPLC analysis of sugars in CDE-supplemented medium before and after bacterial growth is shown in Table 2. Culture $\mathrm{pH}$ was maintained at 6.5 to prevent inhibition of growth by low $\mathrm{pH}$, thus amplifying possible use of $\mathrm{CDE}$ during growth. Sterile medium contained glucose, sorbitol, and Isomalt $^{\circledR}$; mannitol was not detected. Spent culture medium after growth contained reduced concentrations of glucose

Table 2. Concentrations of Isomalt ${ }^{\circledR}$ and Other Sugars in Culture Fluid Before and After pH-Controlled Growth (pH 6.5) of Streptococcus sobrinus 6715

\begin{tabular}{|c|c|c|c|}
\hline \multirow{2}{*}{ Sugar } & \multirow{2}{*}{ Source } & \multicolumn{2}{|c|}{ Concentration, Moles/Liter } \\
\cline { 3 - 4 } & & Sterile Medium & Spent Culture Fluid \\
\hline \hline Glucose & $\begin{array}{c}\text { Trypticase } \\
\text { Broth }\end{array}$ & 0.022 & 0.015 \\
\hline Sorbitol & CDE* & 0.062 & None detected \\
\hline Mannitol & $\mathrm{CDE}$ & None detected & None detected \\
\hline Isomalt & $\mathrm{CDE}$ & 0.119 & 0.034 \\
\hline
\end{tabular}

*CDE: Cough drop extract. and Isomalt ${ }^{\circledR}$; sorbitol and mannitol were not detected. Approximately $71 \%$ of Isomalt ${ }^{\circledR}$ was consumed during growth.

\section{DISCUSSION}

Dental caries is one of the most widespread human infectious diseases [1]. A diet high in fermentable sugars, especially sucrose, is regarded as a major risk factor for this disease [2, 3, 19]. Furthermore, according to the Ecological Plaque Hypothesis frequent and prolonged contact of these sugars with dental plaque alters the microbial composition of plaque in favor of bacteria that are both acidogenic and acid tolerant, thus increasing the cariogenic capacity of dental plaque $[5,6]$. Therefore a major effort in food technology has been to produce confections and snack foods in which sucrose has been replaced by sweeteners that are metabolized very slowly or not at all by oral bacteria, the goal being to greatly reduce or eliminate acid production by plaque following consumption of such foods $[7,20]$.

A number of such sweeteners have been tested and identified as having reduced or low caries risk [9, 21]. Most relevant for this study are the polyols sorbitol, mannitol, and Isomalt $^{\circledR}$ (an equimolar mixture of $\alpha$-D-glucopyranosyl -1,6sorbitol and $\alpha$-D-glucopyranosyl -1,6-mannitol). By in situ measurement of plaque $\mathrm{pH}$, these compounds have been shown to produce minimal drop in plaque $\mathrm{pH}$ following a single brief oral exposure to the agent [9], and studies with pure cultures of oral bacteria have shown that acid production from these sweeteners is quite slow compared to sucrose or glucose $[10,19]$. However, frequent ingestion of sorbitol can lead to increased acid production from dental plaque [22], and "excessive" use of confections containing sorbitol and mannitol can lead to increased levels of mutans streptococci in plaque [23]. Thus it appears that the Ecological Plaque Hypothesis [5, 6] could be invoked in the apparent alteration of dental plaque composition and acidogenicity following frequent and prolonged exposure to at least some slowly metabolized "non-cariogenic" sweeteners.

The present study was precipitated by the occurrence of extensive marginal ditching in an adult patient with a large number of recent restorations. Marginal ditching may be an indicator of marginal or secondary caries, and the bacterial flora of marginal ditches can be enriched for potentially cariogenic mutans streptococci and lactobacilli $[4,10,12]$. The patient was not xerostomic and had an unremarkable history except for the daily use of 8-12 "sugar-free" cough drops over the period of approximately one year. The cough drops were sweetened with the non-metabolizable agent aspartame as well as hydrogenated glucose syrup and Isomalt ${ }^{\circledR}$. The major free constituent of hydrogenated glucose syrup is sorbitol [18], and both sorbitol and Isomalt ${ }^{\circledR}$ are regarded as low-risk for caries [9]. However it has been pointed out that hard candies (e.g., cough drops) are long lasting in the mouth and thus produce extended exposure time in the oral cavity as the sweeteners are gradually released [2]. According to the Ecological Plaque Hypothesis [5, 6], this frequent and prolonged exposure could select for plaque bacteria able to metabolize sorbitol and Isomalt ${ }^{\circledR}$.

The component disaccharides of Isomalt $^{\circledR}$ both are $\alpha$ glucosides and $\alpha$-glucosidase activity is widely distributed in oral bacteria [24-27]. In a survey of 210 strains of mutans streptococci, $100 \%$ of S. sobrinus strains and $91 \%$ of $S$. $m u$ - 
tans strains were positive for $\alpha$-glucosidase activity [24]. Thus it is reasonable to presume that $S$. sobrinus 6715 , used in this study, could degrade Isomalt ${ }^{\circledR}$ to produce glucose, sorbitol, and mannitol. The data show production of acid from CDE and its constituent sugars (Fig. 1 and Table 1) and the consumption of Isomalt ${ }^{\circledR}$ during bacterial growth (Table 2), supporting this contention. Thus, a putative catabolic pathway would begin with $\alpha$-glucosidase-mediated cleavage of Isomalt $^{\circledR}$ to produce glucose, mannitol, and sorbitol, which would be further catabolized via glycolysis yielding a mixture of lactic, acetic, and formic acids [19, 22]. While mannitol and sorbitol are thought to be catabolized slowly, glucose is a rapidly fermented substrate.

As shown in Fig. (1), CDE is both a growth and an acidogenic substrate for $S$. sobrinus 6715 , with a terminal $\mathrm{pH}$ of 4.2 in medium containing $140 \mathrm{mg}$ CDE per $\mathrm{ml}$; this corresponds to approximately $3.84 \%$ of a single cough drop per $\mathrm{ml}$ (data not shown). Table 1 shows that CDE and sugars derived from $\mathrm{CDE}$ also are acidogenic with terminal $\mathrm{pHs}$ ranging from 5.12 (CDE) to 3.90 (glucose); the concentration of CDE used in this experiment corresponds to approximately $1.37 \%$ of a single cough drop per ml.

Dental decay occurs when dental enamel is dissolved by acids made during bacterial metabolism, and the $\mathrm{pH}$ at which this process begins often is described as the "critical" $\mathrm{pH}$. The so-called critical $\mathrm{pH}$ in fact does not have a fixed value but is inversely proportional to concentrations of calcium and phosphate in oral fluids, and can range from 6.5 in a person with low salivary phosphate and calcium to as low as 5.1 in the fluid phase of dental plaque [17]. As shown in Fig. (1) and Table 1, in vitro growth of S. sobrinus 6715 in medium with $\mathrm{CDE}$ can produce culture $\mathrm{pH}$ as low as 5.1, even with only $50 \mathrm{mg} \mathrm{CDE}$ per $\mathrm{ml}$. Even lower pHs were produced with increased concentrations of CDE (Fig. 1).

This study raises a number of questions. Clinical details of tooth damage in affected patients would be valuable. Unfortunately these are not available for the present patient, whose dental records were destroyed and lost when the Louisiana State University School of Dentistry was flooded in the aftermath of Hurricane Katrina. However, there are anecdotal reports of similar tooth damage in other otherwise healthy dental patients who overuse "sugar-free" cough drops (J. Newman, D.M.D., personal communication). It would be interesting to document whether prolonged dietary exposure to Isomalt ${ }^{\circledR}$ would in fact lead to a more acidogenic and acid-tolerant oral microflora as predicted by the Ecological Plaque Hypothesis [5, 6]. However, human and animal trials of excessive use of "sugar-free" cough drops could be both experimentally and ethically problematic. Nevertheless, production of $\alpha$-glucosidase activity is widespread in cariogenic oral streptococci [24], and it would be feasible to examine both the ability of these bacteria to grow on and produce acid from Isomalt ${ }^{\circledR}$ and the enzymatic cleavage of Isomalt ${ }^{\circledR}$ by purified streptococcal $\alpha$-glucosidases.

The clinical picture of our patient and the ability of $S$. mutans 6715 to produce acid from CDE (Fig. 1 and Table 1) and to consume Isomalt ${ }^{\circledR}$ during growth (Table 2) are provocative especially when interpreted in light of the Ecological Plaque Hypothesis [5, 6]. It would seem only prudent to counsel dental patients against chronic and excessive overuse of "sugar-free" cough drops, confections, and snack foods sweetened with Isomalt ${ }^{\circledR}$ and hydrogenated glucose syrup.

\section{ACKNOWLEDGEMENT}

We thank D. Day, N. Thongwai, and D. Kim for performing HPLC analyses.

\section{ABBREVIATION}

$\mathrm{CDE}=\quad$ Cough drop extract

\section{REFERENCES}

[1] Anusavice KJ. Dental caries: risk assessment and treatment solutions for an elderly population. Compend Contin Educ Dent 2002; 23(10 Suppl): 12-20.

[2] Touger-Decker R, van Loveren C. Sugars and dental caries. Am J Clin Nutr 2003; 78(suppl): 881S-92S.

[3] Paes Leme AF, Koo H, Bellato CM, Bedi G, Cury JA. The role of sucrose in cariogenic dental biofilm formation - new insight. J Dent Res 2006; 85: 878-87.

[4] Aas JA, Griffen AL, Dardis SR, et al. Bacteria of dental caries in primary and permanent teeth in children and young adults. J Clin Microbiol 2008; 46: 1407-17.

[5] Marsh PD. Microbial ecology of dental plaque and its significance in health and disease. Adv Dent Res 1994; 8: 263-71.

[6] Marsh PD. Dental plaque as a biofilm and a microbial community implications for health and disease. BMC Oral Health 2006; 6 (Suppl 1): S14

[7] Grenby TH, Mistry M. Laboratory studies of sweets re-formulated to improve their dental properties. Oral Dis 1996; 2: 32-40.

[8] Food and Drug Administration. Health claims: Dietary sugar alcohols and dental caries. Fed Reg 1996; 61: 43433-45.

[9] Imfeld TN. Identification of low caries risk dietary components Monogr Oral Sci 1983; 11: 1-198.

[10] van der Hoeven JS. Cariogenicity of disaccharide alcohols in rats. Caries Res 1980; 14: 61-66.

[11] Kidd EAM, Beighton D. Prediction of secondary caries around tooth-colored restorations: a clinical and microbiological study. J Dent Res 1996; 75: 1942-6.

[12] Kidd EAM, Joyston-Bechal S, Beighton D. Marginal ditching and staining as a predictor of secondary caries around amalgam restorations: a clinical and microbiological study. J Dent Res 1995; 74: 1206-11.

[13] Dubroc GC, Mayo JA, Rankine CAN. Reduction of caries and of demineralization around orthodontic brackets: Effect of a fluoridereleasing resin in the rat model. Am J Orthodont Dentofacial Orthoped 1994; 106: 583-7.

[14] Nelson D, Goldstein JM, Boatright K, et al. pH-Regulated secretion of a glyceraldehyde-3-phosphate dehydrogenase from Streptococcus gordonii FSS2: purification, characterization, and cloning of the gene encoding this enzyme. J Dent Res 2001; 80: 371-7.

[15] van Houte J, Saxton CA. Cell wall thickening and intracellular polysaccharide in microorganisms of the dental plaque. Caries Res 1971; 5: 30-43.

[16] Corradini C, Canali G, Cogliandro E, Nicoletti I. Separation of alditols of interest in food products by high-performance anionexchange chromatography with pulsed amperometric detection. J Chromatogr A 1997; 791: 343-9.

[17] Dawes C. What is the critical $\mathrm{pH}$ and why does a tooth dissolve in acid? J Can Dent Assoc 2003; 69: 722-4.

[18] Rerat A, Giusi-Perier A, Vaissade P. Absorption balances and kinetics of nutrients and bacterial metabolites in conscious pigs af ter intake of maltose- or maltitol-rich diets. J Anim Sci 1993; 71: 2473-88.

[19] Navia JM. Carbohydrates and dental health. Am J Clin Nutr 1994; 59(suppl): 719S-27S

[20] Edgar WM, Dodds MWJ. The effect of sweeteners on acid production in plaque. Int Dent J 1985; 35: 18-22.

[21] Matsukubo T, Takazoe I. Sucrose substitutes and their role in caries prevention. Int Dent J 2006; 56: 119-30.

[22] Birkhed D, Kalfas S, Svensäter G, Edwardsson S. Microbiological aspects of some caloric sugar substitutes. Int Dent J 1985; 35: 9-17. 
[23] Loesche WJ. The effect of sugar alcohols on plaque and saliva level of Streptococcus mutans. Swed Dent J 1984; 8: 125-35.

[24] Beighton D, Russell RR, Whiley RA. A simple biochemical scheme for the differentiation of Streptococcus mutans and Streptococcus sobrinus. Caries Res 1991; 25: 174-8

[25] Glor EB, Miller CH, Spandau DF. Degradation of starch and its hydrolytic products by oral bacteria. J Dent Res 1988; 67: 75-81.
[26] Laughon BE, Syed SA, Loesche WJ. API ZYM system for identification of Bacteroides spp., Capnocytophaga spp., and spirochetes of oral origin. J Clin Microbiol 1982; 15: 97-102.

[27] Tanner AC, Strzempko MN, Belsky CA, McKinley GA. API ZYM and API An-Ident reactions of fastidious oral gram-negative species. J Clin Microbiol 1985; 22: 333-5.

(C) Mayo and Ritchie; Licensee Bentham Open.

This is an open access article licensed under the terms of the Creative Commons Attribution Non-Commercial License (http://creativecommons.org/licenses/ by-nc/3.0/) which permits unrestricted, non-commercial use, distribution and reproduction in any medium, provided the work is properly cited. 